\title{
EXPOSURE TO CONCOMITANT LOW HEALTH-RELATED PHYSICAL FITNESS COMPONENTS AND ASSOCIATED SOCIODEMOGRAPHIC FACTORS IN BRAZILIAN ADOLESCENTS
}

doi: 10.2478/v10038-012-0035-0

\author{
GISELI MINATTO ${ }^{1,2}$ *, EDIO LUIZ PETROSKI ${ }^{1}$, DIEGO AUGUSTO SANTOS SILVA ${ }^{1}$ \\ ${ }^{1}$ Sports Center, Center for Research in Kinanthropometry and Human Performance, \\ Federal University of Santa Catarina, Florianópolis, Brazil \\ ${ }^{2}$ CAPES scholar
}

\begin{abstract}
Purpose. To determine the prevalence of the presence of concomitant low health-related physical fitness components with sociodemographic factors among Brazilian adolescents living in a small town of German colonization. Methods. A cross-sectional epidemiological study on adolescents (10 to 17 years old) from the public schools of São Bonifácio, Santa Catarina, Brazil $(N=277)$ was conducted. The FITNESSGRAM test battery was applied to assess three physical fitness components (body composition, cardiorespiratory and muscular fitness). Data on age (split into two age groups of 10-12 and 13-17 years), gender (male/ female), area of residence (rural/urban) and socioeconomic status (low/high) were collected by a questionnaire. Maturity, determined by pubic hair development, was self-assessed. The analyzed physical fitness components were analyzed in terms of the groups of three possible combinations that featured two physical fitness components concomitantly. Adjusted binary and multinomial logistic regression was applied, adopting a confidence level of $95 \%$. Results. $75.4 \%$ of boys and $88.5 \%$ of girls showed unsatisfactory levels for health in at least one physical fitness component. Girls living in rural areas were more likely to have combinations of excess body fat with low muscular fitness ( $\mathrm{OR}=5.06,95 \%$ CI $[1.31,19.61])$, low muscular fitness with low cardiorespiratory fitness $(\mathrm{OR}=5.46,95 \% \mathrm{CI}[1.24,23.94])$ and feature two $(\mathrm{OR}=8.82,95 \% \mathrm{CI}[1.60,48.49])$ low values of the components regardless of which combination. Boys aged 10-12 years were less exposed to lower fitness levels compared to those with satisfactory levels $(\mathrm{OR}=0.09,95 \% \mathrm{CI}[0.01,0.61])$. Conclusions. More effective measures aimed at promoting physical fitness among adolescents are needed, where special attention should be given to boys aged 10-12 years and girls aged 13-17 years and living in rural areas.
\end{abstract}

Key words: physical fitness, adiposity, students, socioeconomic status, Brazil

\section{Introduction}

Health-related physical fitness is based on morphological, functional and motor factors that respectively correspond to body composition, cardiorespiratory fitness and muscular fitness (flexibility, power and muscular strength). Researchers [1] have revealed that adolescents who have poor physical fitness in all of the health-related components are more likely to have a higher risk factor for metabolic syndrome.

Excess body fat acquired early in life contributes to the early onset of non-communicable chronic diseases such as cardiovascular disease, hypertension and type II diabetes [2]. Muscular fitness (power/muscular strength) has been inversely associated with death from all causes [3], and adequate cardiorespiratory fitness, regardless of body fat, has shown a lower prevalence of risk factors for cardiovascular disease $[4,5]$. In obese adolescents, low physical fitness has been associated with elevated symptoms of depression [6].

In adolescence, the components of health-related physical fitness are also associated with sociodemogra-

* Corresponding author. phic indicators such as area of residence and socioeconomic status [7-11]. Those living in rural areas with better socioeconomic status feature better cardiorespiratory fitness compared to their urban peers and those with lower socioeconomic status $[7,9,12]$. In relation to body composition, inadequate levels are less prevalent among rural adolescents [13]. However, a higher probability of featuring excess body fat has been observed in adolescents with higher socioeconomic status $[14,15]$, a characteristic that has been observed in developing countries such as Brazil.

Although there are some studies in international literature that were found to concomitantly analyze the components of health-related physical fitness in adolescents and its associated factors $[1,4,5]$, most of them were limited by only concentrating on associations between excess body fat and low cardiopulmonary fitness $[4,5]$. In addition, these surveys were conducted on Portuguese [1, 4] and American adolescents [5]; no Brazilian studies investigating the presence of the components of low health-related physical fitness and its associated factors were found.

Brazilian studies that did address this problem were found to separately analyze the physical fitness components and its associated factors $[9,10]$ or only study 
G. Minatto, E.L. Petroski, D.A.S. Silva, Health-related physical fitness in adolescents

how these physical fitness components are associated with each other [16, 17]. Given that the presence of low physical fitness levels promotes the occurrence of risk factors in health [2-5] and that these are related to sociodemographic factors [7-11], it was considered essential to evaluate these factors at an early age and analyze them according to these outlined parameters. One reason being that adolescence is considered a period of numerous lifestyle changes that may contribute towards maintaining satisfactory physical fitness levels later in adulthood [18].

Thus, the objective of this study was to determine the prevalence of the presence of low health-related physical fitness components concomitant with associated sociodemographic factors (age, area of residence and socioeconomic status) among Brazilian adolescents (10 to 17 years old) living in a small town formerly colonized by German settlers.

\section{Material and methods}

\section{Study design and participants}

Analysis on the health-related physical fitness of adolescents and its associated factors was developed as part of a cross-sectional epidemiological project entitled "Physical activity and lifestyle: a study of three generations in São Bonifácio, Santa Catarina”. It was approved by the Ethics Committee on Human Research at the Federal University of Santa Catarina (UFSC), process No. $973 / 10$. To date, this is the only study conducted on adolescents from São Bonifácio, a town in Santa Catarina (SC), a state located in the southern part of Brazil. This city was intentionally selected due to its population makeup of individuals with German ancestry. The first Europeans that settled in Santa Catarina were German and they are considered to be the second largest ethnic group in the region after those with Italian ancestry. Although immigrants from various European countries have settled in the state, Germans make up the majority in the northern and southern part of Santa Catarina, with São Bonifácio standing out as being colonized only by Germans [19] starting from the year 1864.

In 2010, the population consisted of 3008 inhabitants with $77.23 \%$ living in rural areas. The city's economy is based on largely on agriculture, with emphasis on tobacco, horticulture and dairy production [20]. With a Human Development Index of 0.785, São Bonifácio is classified as having an intermediate human development index [21].

A census was conducted among São Bonifácio's schools, which included one state and four municipal public schools. Based on the World Health Organization's definition [2] of adolescence, only individuals aged 10 to 17 years were invited to take part in the study. A total of 291 adolescents agreed to participate; the remaining eligibility criteria required that the student present a consent form signed by their parents, to be present at school on the day of the assessment and to be able to perform the physical tests.

Adolescents without a signed consent term $(n=3)$, those who were absent on the day of the assessment $(n=5)$, those who refused to participate in the study $(n=5)$ and those who had some motor limitation impairing their ability to complete the physical tests on the day of assessment $(n=1)$ were excluded from the final sample, resulting in a total of 277 adolescents (145 boys and 132 girls) that took part in the study.

\section{Data collection}

A team of evaluators, composed of 14 teachers and students taking a university course in physical education, volunteered to assist in data collection. A pilot study was conducted on a sample of adolescents with characteristics similar to the study population in order to test the measurement instruments and the time required to perform each physical test.

Data were collected over a period of seven days in September 2010 on school grounds and during class time. Each evaluator was responsible for the same test from the beginning to end of data collection. The health-related physical fitness components investigated were: body composition, muscular fitness and cardiorespiratory fitness. Fat percentage was used to assess body composition. The first step in data collection consisted of taking the adolescents' anthropometric measurements (body weight, height and skinfold thickness). Then, the adolescents were taken to their school's multi-sports gymnasium where the physical tests were conducted and sexual maturation was assessed. No warm-up exercises were performed prior to the physical fitness tests.

\section{Anthropometry}

Body mass was measured using a digital scale (Filizola, Brazil) with a measurement capacity of $150 \mathrm{~kg}$ and accurate to $100 \mathrm{~g}$. Height was obtained using a stadiometer (Sanny, Brazil) with an accuracy of $0.1 \mathrm{~cm}$. Triceps (TRSF) and subscapular skinfolds (SSSF) were collected using a scientific adipometer (Cescorf, Brazil), a model similar in mechanical design to the adipometer made by Harpenden (United Kingdom), which provides a constant jaw pressure of $10 \mathrm{~g} / \mathrm{mm}^{2}$, is accurate to $0.1 \mathrm{~mm}$ and has a contact area (surface) of $90 \mathrm{~mm}^{2}$. The measurements were performed by two trained evaluators. For this measurement, prior to data collection, the intra-and inter-evaluator Technical Error of Measurement (TEM) was calculated on a sample of 17 adolescents using the difference method based on the procedures outlined by Gore et al. [22]. The intra-evaluator TEM limit was found to be $3 \%$ for skinfolds and $1 \%$ for other measures. For inter-evaluator TEM, an error limit of 7\% for skinfolds and $1 \%$ for other measures were adopted. To 
evaluate body composition, TRSF and SSSF were used in calculating the body fat percentage using Slaughter et al.'s formula [23].

\section{Physical fitness}

Muscular fitness was assessed by evaluating flexibility (back-saver sit and reach) and muscle strength/ endurance (curl-up and modified pull-up). The backsaver sit and reach test was performed with the help of a wooden box $30 \mathrm{~cm}$ in height on which a measuring ruler was placed sticking $22.5 \mathrm{~cm}$ out from the edge of the box from where the subject placed their feet; the "zero" end of the ruler was placed nearest to the subject.

The subject executed the test with one leg completely extended and brought up to rest flat on the box; the other leg was bent with the sole of the foot flat on the floor. The subject then performed a forward trunk flexion with arms extended, hands placed one on top of the other with palms down, trying to bend as far forward as possible on the measuring stick. The same procedure was performed a total four times by switching the position of the legs, and the highest measurement obtained for each leg was recorded. The accuracy of this measurement was within $0.1 \mathrm{~cm}$. Due to the high correlation between flexibility of the right and left legs $(r=0.92)$, the mean of both measurements was used.

In the curl-up test, subjects had to complete as many curl-ups as possible (up to a maximum of 75) so as to comply with the established execution cadence of 20 repetitions per minute, or one repetition every three seconds. A gym mat was used with two $11.5 \mathrm{~cm}$ measurement strips fixed on both sides. The subject was to lie in a supine position on the mat, knees bent at an angle of approximately $140^{\circ}$, feet flat on the floor, legs slightly apart, arms straight and parallel to the trunk with the palms resting on the mat and fingers stretched out and the head in contact with the mat. The subject was positioned so that their fingertips rested on the nearest edge of the first measuring strip. To execute the trunk flexion, the subject slowly slid their fingers across the measuring strip until they reached the opposite end, which signified they properly executed a curl-up. The number of correctly performed repetitions was recorded.

For the modified pull-up test, a bar and an elevated support were used. The subject lay on a gym mat in the supine position with shoulders facing the hanging bar, which was set three to five $\mathrm{cm}$ above the subject's grasp. An elastic band was placed approximately $15 \mathrm{~cm}$ below and parallel to the bar. With an overhand grip, the subject grasped the bar at a grip equivalent to shoulder width. The exercise began by being suspended (arms and legs straight) in the "down" position, buttocks off the floor and with only the heels touching the floor. The subject then continuously pulled their body up until the chin was above the band. The test was finished when either the subject was physically unable to perform any- more repetitions or when the subject performed two incorrect repetitions in a row. Only the number of correctly performed repetitions was recorded.

A 20-m shuttle run test was used to assess adolescents' cardiorespiratory fitness and consisted of running between two points 20 meters apart from each other at an increasing speed. Running speed was paced by the use of an audio signal that required the participants to complete the 20-m course before the sound of a beep. The initial speed of the test was $8.5 \mathrm{~km} / \mathrm{h}$, progressively increased by $0.5 \mathrm{~km} / \mathrm{h}$ every minute. The test continued to increase the running speed and terminated once an individual was unable to keep up with the audio cadence and failed to finish the 20-m distance before the beep was heard. The speed of the last successfully completed lap was then recorded. Data from the test were analyzed by using a formula proposed by Léger et al. [24] to estimate maximal oxygen uptake $\left(\mathrm{VO}_{2} \max \right): \mathrm{Y}=31.025+$ $(3.238 \cdot \mathrm{X} 1)-(3.248 \cdot \mathrm{X} 2)+(0.1536 \cdot[\mathrm{X} 1 \cdot \mathrm{X} 2])$, in which $\mathrm{Y}$ was the predicted value of $\mathrm{VO}_{2} \mathrm{max}$ in $\mathrm{ml} / \mathrm{kg} / \mathrm{min}$, $\mathrm{X} 1=$ Running speed corresponding to the stage in $\mathrm{km} / \mathrm{h}$ and $\mathrm{X} 2$ = Subject's age.

The recommended procedures proposed by the FITNESSGRAM [25] were adopted for completing the physical tests as well as the suggested cutoff points for this test battery [26] in order to to determine the proportion of adolescents who did not meet the health criteria specific for sex and age.

\section{Sociodemographic variables}

Sociodemographic data were collected for age, sex, area of residence and socioeconomic status. For later analysis, age was dichotomized into two groups consisting of younger (10-12 years) and older (13-17 years) adolescents. Sex (male/female) and area of residence (rural/urban) were self-reported.

To define socioeconomic status, the guidelines proposed by the Brazilian Association of Research Companies (ABEP) [27] were used, which estimate the purchasing power of families and ranks them from richest to poorest (A1, A2, B1, B2, C1, C2, D and E) based on the accumulation of material goods, housing conditions, number of working individuals in the household and the education level of the household head. Due to the small number of subjects in this study, categories A and $\mathrm{B}$ were classified as having high socioeconomic status and categories $\mathrm{C}, \mathrm{D}$ and $\mathrm{E}$ as having low status. This questionnaires were given to the adolescents to be taken home and filled out by their parents and returned to school the next day.

\section{Sexual maturation}

Sexual maturity was self-assessed by the participants by classifying their pubic hair development, as proposed by Tanner [28] and elaborated by the Department of Nu- 
G. Minatto, E.L. Petroski, D.A.S. Silva, Health-related physical fitness in adolescents

trition at the UFSC (Kendall's correlation coefficient of $0.627[p<0.01]$ for boys and $0.739[p<0.01]$ for girls) [29]. Assistance was provided by an evaluator of the same sex as the adolescent. In this procedure, students were individually instructed in a private room where their evaluator explained the importance and objectives of the sexual maturation assessment. The evaluator then described the required procedure and on how to fill out the evaluation form. The participants were shown a board with photographs of five stages of pubic hair development, asked to carefully note the differences in each of the photographs and then rate which photograph best resembled his/her pubic hair development on the evaluation form.

\section{Statistical analysis}

Absolute ( $n$ ) and relative (\%) frequency, median, mean, standard deviation and inter-quartile interval values were used for descriptive analysis of the studied variables. The normality of the data was assessed using the Kolmogorov-Smirnov test separately for each sex. Normal distribution for flexibility and body fat percentage was found after applying $\log _{10}$ data transformation. To compare the average values between sexes, the Student's $t$-test was used for variables showing normal distribution (flexibility and body fat percentage), while its non-parametric equivalent (the Mann-Whitney $U$ test) was used for the other tested variables (curl-up, modified pull-up and 20-m shuttle run [ $\left.\mathrm{VO}_{2} \mathrm{max}\right]$ tests). The muscle strength/endurance and flexibility tests were added to the "muscular fitness" variable [25]. Adolescents who had excess body fat and/or those who did not meet the recommended health criteria in at least one of the three muscular fitness and/or cardiorespiratory fitness tests were considered to feature low physical fitness.

A "simultaneity" variable was created from the sum of the presented health-related physical fitness components that did not meet the criteria proposed by the FITNESSGRAM, categorized as featuring none, one, two or three components that define health risks. Three other dependent variables relating to the possible combinations of two components were also created: Combination 1 (excess body fat and low muscular fitness), Combination 2 (excess body fat and low cardiorespiratory fitness), Combination 3 (low muscular fitness and low cardiorespiratory fitness). In this assessment, adolescents who did not undergo all of the physical test or skinfolds evaluation were excluded $(n=9)$.

The prevalence of low health-related physical fitness components, both separately and concomitantly, were estimated by relative frequency distribution. Differences between sex were determined by the confidence intervals of prevalence.

For regression analysis of the various combinations of low physical fitness components, three binary logistic regressions were performed to estimate the odds ratios and confidence intervals, considered as dependent variables, after adjusting for all independent variables. For the "simultaneity" variable, an adjusted multinomial regression was performed for all independent variables and no component was considered as the reference category when estimating the odds ratios and confidence intervals. The adopted confidence level adopted was at 95\% and the significance level was adopted at 5\%. Data were entered into Microsoft Excel software and analyzed using Statistical Package for Social Sciences (SPSS, IBM, USA), version 15.0.

\section{Results}

Table 1 shows the general characteristics of the adolescents (10 to 17 years of age) according to sex. Girls showed higher TRSF, SESF, body fat percentage and flexibility values. Boys showed higher mean values in the power/muscular strength and cardiorespiratory fitness tests.

The sociodemographic characteristics of adolescents stratified by sex, area of residence and socioeconomic status are shown in Table 2. A higher frequency of boys aged $13-17$ years $(51.7 \%)$, living in rural areas $(69.3 \%)$ and belonging to low socioeconomic status (56.5\%) was observed. A higher frequency of girls aged 13-17 years $(56.8 \%)$, living in rural areas $(67.2 \%)$ and high socioeconomic status (55.1\%) was observed.

Figure 1 shows that excess body fat was present in one out of three adolescents, for boys at 95\% CI [21.3, $36.4]$ and girls at 95\% CI [23.7, 39.9] ( $p>0.05)$. The prevalence of low muscular fitness was found in more than half of the boys at 95\% CI $[60.2,76.0]$ and most of the girls at 95\% CI $[80.1,92.2](p \leq 0.05)$. The proportion of adolescents with low cardiorespiratory fitness was similar between boys at 95\% CI [20.0, 35.1] and girls at 95\% CI [28.5, 45.9].

In the adjusted logistic regression analysis for all independent variables (Tab. 3), girls living in rural areas were more exposed to low levels of combined excess body fat and muscular fitness $(\mathrm{OR}=5.06,95 \% \mathrm{CI}[1.31$, 19.61]) and muscular fitness and cardiorespiratory fitness $(\mathrm{OR}=5.46,95 \%$ CI $[1.24,23.94])$ compared to those living in urban areas. The chances of presenting excess body fat and low muscle fitness were lower among girls 10-12 years of age when compared to those 13-17 years of age. No associations were found between the three combinations and sociodemographic factors for boys and socioeconomic level for girls $(p>0.05)$.

When low fitness components were grouped (Fig. 2), it was observed that $75.4 \%$ of boys and $88.5 \%$ of girls showed unsatisfactory health levels in at least one fitness component. Differences between sexes were observed only for adolescents not exposed to low physical fitness components, being more prevalent in boys at $95 \%$ CI $[18.1,32.6]$ than in girls at 95\% CI $[6.0,17.1]$. 
Table 1. General characteristics of the participants

\begin{tabular}{|c|c|c|c|c|c|c|c|c|c|c|c|}
\hline \multirow{2}{*}{ Variables } & \multicolumn{5}{|c|}{ Boys } & \multicolumn{5}{|c|}{ Girls } & \multirow{2}{*}{$p$-value } \\
\hline & $n$ & $\bar{x}$ & SD & Md & IIQ & $n$ & $\bar{x}$ & SD & Md & IIQ & \\
\hline $\begin{array}{l}\text { Chronological age } \\
\text { (years) }\end{array}$ & 140 & 12.97 & 2.32 & 13.00 & $11.00-15.00$ & 130 & 13.18 & 2.12 & 13.00 & $11.00-15.00$ & 0.307 \\
\hline Body mass (kg) & 140 & 53.64 & 16.41 & 54.00 & $41.70-62.80$ & 130 & 54.36 & 14.80 & 54.85 & $44.35-62.88$ & 0.725 \\
\hline Height (cm) & 140 & 159.27 & 14.76 & 160.50 & $146.88-172.55$ & 130 & 159.82 & 10.32 & 162.85 & $153.08-167.10$ & 0.881 \\
\hline TSF (mm) & 140 & 13.52 & 6.89 & 11.35 & $8.00-17.18$ & 130 & 18.44 & 6.82 & 17.35 & $13.62-21.88$ & 0.000 \\
\hline SSF (mm) & 145 & 11.32 & 8.07 & 8.05 & $6.38-13.05$ & 130 & 14.23 & 8.99 & 11.50 & $8.43-16.38$ & 0.000 \\
\hline Body fat (\%) & 140 & 20.97 & 11.36 & 16.82 & $13.18-26.93$ & 130 & 26.69 & 8.88 & 25.17 & $21.28-31.94$ & 0.000 \\
\hline Flexibility $(\mathrm{cm})$ & 140 & 22.79 & 6.15 & 22,50 & $18.93-26,31$ & 130 & 26.02 & 5.35 & 26.50 & $22.56-30.00$ & 0.000 \\
\hline $\begin{array}{l}\text { Curl-ups } \\
\text { (repetitions) }\end{array}$ & 140 & 26.14 & 20.76 & 21.50 & $12.00-34.25$ & 130 & 23.59 & 19.32 & 19.50 & $10.00-30.00$ & 0.229 \\
\hline $\begin{array}{l}\text { Pull-ups } \\
\text { (repetitions) }\end{array}$ & 140 & 8.26 & 5.65 & 7.00 & $3.00-12.00$ & 130 & 3.29 & 2.77 & 3.00 & $1.00-5.00$ & 0.000 \\
\hline $\begin{array}{l}\text { Cardiorespiratory } \\
\text { fitness }\left(\mathrm{VO}_{2} \max \right)\end{array}$ & 138 & 44.23 & 4.62 & 44.55 & $41.42-47.40$ & 128 & 40.56 & 5.12 & 41.15 & $37.35-44.57$ & 0.000 \\
\hline
\end{tabular}

$\bar{x}$ - mean; SD - standard deviation; Md - median; TSF - triceps skinfold thickness; SSF - subscapular skinfold thickness; IIQ - inter-quartile interval; $p$-value based on the Student's $t$-test for body mass, TSF, percent body fat and flexibility.

For the other variables, the Mann-Whitney $U$ test (chronological age, height, SSF, curl-up, pull-ups, and cardiorespiratory fitness) was used

Table 2. Distribution of sociodemographic variables according to sex among adolescents

\begin{tabular}{|c|c|c|c|c|c|c|}
\hline \multirow{2}{*}{ Variables } & \multicolumn{2}{|c|}{ Boys } & \multicolumn{2}{|c|}{ Girls } & \multicolumn{2}{|c|}{ Total } \\
\hline & $n$ & $\%$ & $n$ & $\%$ & $n$ & $\%$ \\
\hline \multicolumn{7}{|l|}{ Age $(n=277)$} \\
\hline 10-12 years & 70 & 48.3 & 57 & 43.2 & 127 & 45.8 \\
\hline 13-17 years & 75 & 51.7 & 75 & 56.8 & 150 & 54.2 \\
\hline \multicolumn{7}{|c|}{ Residence $(n=265)$} \\
\hline Rural & 95 & 69.3 & 86 & 67.2 & 181 & 68.3 \\
\hline Urban & 42 & 30.7 & 42 & 32.8 & 84 & 31.7 \\
\hline \multicolumn{7}{|l|}{$\operatorname{SES}(n=231)$} \\
\hline Low & 70 & 56.5 & 48 & 44.9 & 118 & 51.1 \\
\hline High & 54 & 43.5 & 59 & 55.1 & 113 & 48.9 \\
\hline
\end{tabular}

SES - socioeconomic status

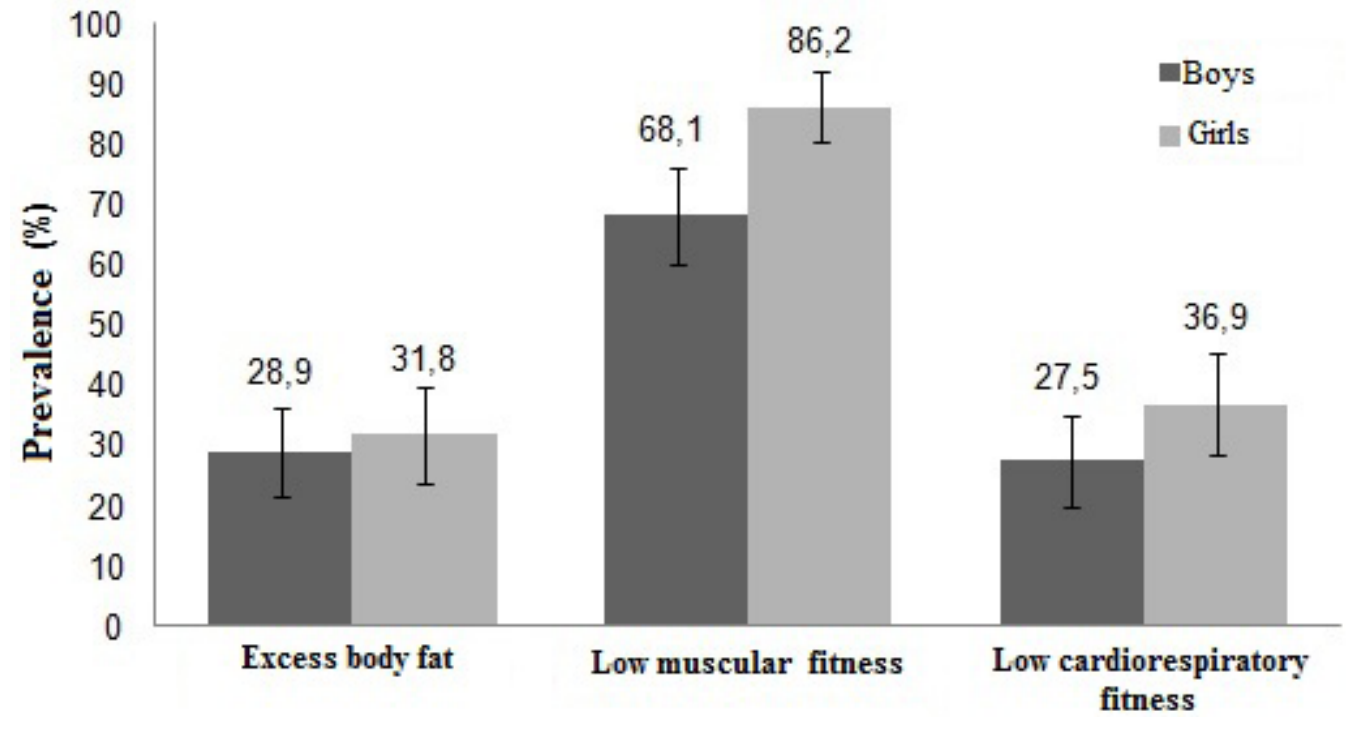

Figure 1. Prevalence and 95\% confidence level of low health-related physical fitness components according to sex 


\section{HUMAN MOVEMENT}

G. Minatto, E.L. Petroski, D.A.S. Silva, Health-related physical fitness in adolescents

Table 3. Binary logistic regression analysis for combinations of two low health-related physical fitness components adjusted for sociodemographic variables and sexual maturation

\begin{tabular}{|c|c|c|c|c|c|c|}
\hline \multirow{2}{*}{ Variables } & \multicolumn{2}{|c|}{$\begin{array}{l}\text { Excess body fat } x \\
\text { low muscular fitness }\end{array}$} & \multicolumn{2}{|c|}{$\begin{array}{c}\text { Excess body fat } x \\
\text { low cardiorespiratory fitness }\end{array}$} & \multicolumn{2}{|c|}{$\begin{array}{l}\text { Low muscular fitness } \times \\
\text { low cardiorespiratory fitness }\end{array}$} \\
\hline & $\mathrm{OR}^{\dagger}$ & $95 \%$ CI & $\mathrm{OR}^{\dagger}$ & $95 \%$ CI & $\mathrm{OR}^{\dagger}$ & $95 \%$ CI \\
\hline \multicolumn{7}{|l|}{ Boys } \\
\hline \multicolumn{2}{|c|}{ Age (years) } & $0.33-2.04$ & 0.54 & $0.23-1.24$ & 0.42 & $0.16-1.10$ \\
\hline $13-17$ & 1 & & 1 & & 1 & \\
\hline \multicolumn{7}{|l|}{ Residence } \\
\hline Rural & 1.17 & $0.51-2.69$ & 0.93 & $0.42-2.03$ & 1.05 & $0.44-2.49$ \\
\hline Urban & 1 & & 1 & & 1 & \\
\hline \multicolumn{7}{|l|}{ SES } \\
\hline Low & 1.14 & $0.52-2.53$ & 1.03 & $0.49-2.17$ & 1.21 & $0.53-2.77$ \\
\hline High & 1 & & 1 & & 1 & \\
\hline \multicolumn{7}{|l|}{ GIRLS } \\
\hline \multicolumn{7}{|c|}{ Age (years) } \\
\hline $10-12$ & 0.74 & $0.20-2.78$ & 0.35 & $0.15-0.85^{*}$ & 0.33 & $0.07-1.46$ \\
\hline $13-17$ & 1 & & 1 & & 1 & \\
\hline \multicolumn{6}{|l|}{ Residence } & $1.24-23.94 *$ \\
\hline Urban & 1 & & 1 & & 1 & \\
\hline \multicolumn{7}{|l|}{ SES } \\
\hline Low & 1.20 & $0.30-4.73$ & 0.97 & $0.40-2.36$ & 3.02 & $0.55-16.40$ \\
\hline High & 1 & & 1 & & 1 & \\
\hline
\end{tabular}

OR - odds ratio, 95\% CI - confidence interval of 95\%, SES - socioeconomic status,

$* p \leq 0.05, \dagger$ analysis adjusted for all sociodemographic variables and sexual maturation

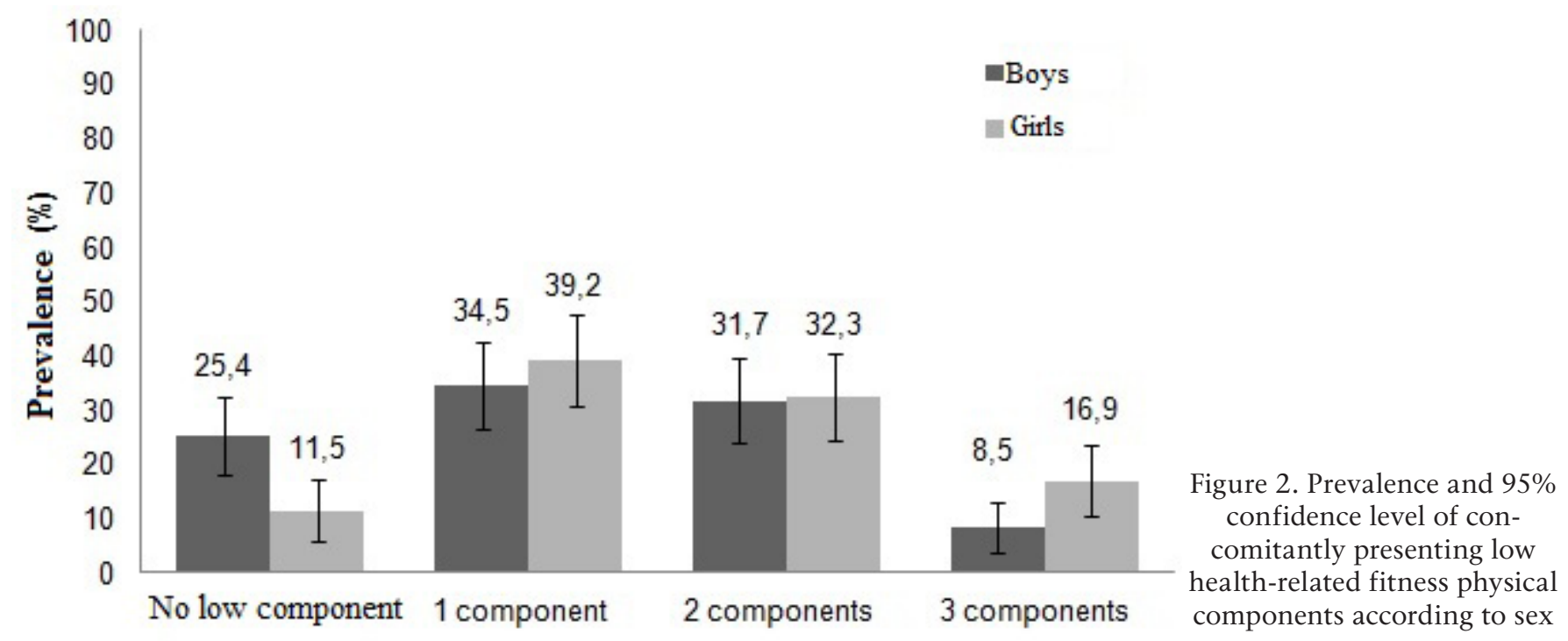

In the analysis of the concomitant presence of low physical fitness levels in the three investigated components (Tab. 4), adjusted for all sociodemographic variables and sexual maturation, a relationship was found in girls and boys. Girls living in rural areas were 8.82 times more likely to present low physical fitness levels in two components, regardless of which two components, compared to those with adequate body composition, cardiorespiratory fitness and muscular fitness levels. Boys aged 10-12 years had lower odds of presenting low levels of physical fitness in all components $(\mathrm{OR}=0.09,95 \% \mathrm{CI}[0.01,0.61])$ compared to those with satisfactory levels. The age and socioeconomic level variables for girls and the area of residence and socioeconomic level variables for boys, controlled for sexual maturation, were not associated with the concomitant presence of the physical fitness components $(p>0.05)$. 
Table 4. Multinomial regression analysis of the low health-related physical fitness components adjusted for sociodemographic variables and sexual maturation

\begin{tabular}{|c|c|c|c|c|c|c|}
\hline \multirow{2}{*}{ Variables } & \multicolumn{2}{|c|}{1 component } & \multicolumn{2}{|c|}{2 components } & \multicolumn{2}{|c|}{3 components } \\
\hline & $\mathrm{OR}^{\dagger}$ & $95 \% \mathrm{CI}$ & $\mathrm{OR}^{\dagger}$ & $95 \% \mathrm{CI}$ & $\mathrm{OR}^{\dagger}$ & $95 \% \mathrm{CI}$ \\
\hline \multicolumn{7}{|l|}{ Boys } \\
\hline \multicolumn{7}{|c|}{ Age (years) } \\
\hline $10-12$ & 0.62 & $0.20-1.93$ & 0.73 & $0.23-2.26$ & 0.09 & $0.01-0.61$ * \\
\hline $13-17$ & 1 & & 1 & & 1 & \\
\hline \multicolumn{7}{|l|}{ Residence } \\
\hline Rural & 1.73 & $0.62-4.88$ & 1.02 & $0.37-2.79$ & 0.90 & $0.20-4.12$ \\
\hline Urban & 1 & & 1 & & 1 & \\
\hline \multicolumn{7}{|l|}{ SES } \\
\hline Low & 2.02 & $0.76-5.40$ & 1.19 & $0.45-3.16$ & 0.80 & $0.18-3.59$ \\
\hline High & 1 & & 1 & & 1 & \\
\hline \multicolumn{7}{|l|}{ GIRLS } \\
\hline \multicolumn{7}{|c|}{ Age (years) } \\
\hline $10-12$ & 0.63 & $0.13-3.06$ & 0.29 & $0.06-1.55$ & 0.19 & $0.03-1.20$ \\
\hline $13-17$ & 1 & & 1 & & 1 & \\
\hline \multicolumn{7}{|l|}{ Residence } \\
\hline Rural & 3.25 & $0.68-15.46$ & 8.82 & $1.60-48.49^{*}$ & 5.48 & $0.86-34.97$ \\
\hline Urban & 1 & & 1 & & 1 & \\
\hline \multicolumn{7}{|l|}{ SES } \\
\hline Low & 3.26 & $0.57-18.67$ & 2.17 & $0.35-13.63$ & 2.25 & $0.31-16.36$ \\
\hline High & 1 & & 1 & & 1 & \\
\hline
\end{tabular}

Reference category = no low component; OR - odds ratio, 95\% CI - confidence interval of 95\%, SES - socioeconomic status, $* p \leq 0.05, \dagger$ analysis adjusted for all sociodemographic variables and sexual maturation

\section{Discussion}

The main findings of this study, considering the cutoff points adopted for body fat percentage and cardiorespiratory fitness of girls and boys, reveal that the prevalence of low physical fitness was similar between sexes except for low muscular fitness, which was proportionally higher in girls. The proportion of adolescents with satisfactory physical fitness levels in all components differed between sexes, being more prevalent in boys. The chance of showing a combination of excess body fat and low muscular fitness, and low cardiorespiratory and muscular fitness levels, were higher for girls living in rural areas. Girls 10-12 years of age were less exposed to the combination of excess body fat and low cardiorespiratory fitness. Concomitantly presenting unsatisfactory physical fitness levels in two of the studied components was higher for girls living in rural areas and less in boys aged 10-12 years.

The proportion of adolescents with excess body fat and low cardiorespiratory and muscular fitness found in this study is consistent to that found in other Brazilian cities $[9,15,30,31]$. The prevalence of low physical fitness in terms of cardiorespiratory fitness was observed in a city in southern Brazil (68.0\% of boys and 37.8\% of girls) [9] and one in southeastern Brazil [15] in terms of body composition (24.1\%), flexibility (40.8\%), muscle strength/endurance $(98.5 \%)$ and cardiorespiratory fitness $(35.4 \%)$, although these studies adopted different classification criteria. The prevalence level found in this study was higher than those observed in Portuguese adolescents [4] for body composition and cardiorespiratory fitness components and lower than those found in Europeans adolescents [32] for cardiorespiratory fitness. The prevalence of adolescents with low physical fitness is alarming, given the risk of hypokinetic diseases such as obesity, which may arise already in childhood and early adolescence. On the other hand, adolescents who meet the health criterion for all physical fitness components are less exposed to metabolic risk factors [1].

Younger girls (10-12 years) were less likely to present combination of excess body fat with low cardiorespiratory fitness levels, when analyzed by the cutoff points used in this study, in relation to older girls. Similar results were observed in girls from Brazilian cities $[9,10]$ in studies analyzing the physical fitness components separately. In girls, the process of sexual maturation occurs early in adolescence, which gives increased body size and muscular mass and leads, therefore, to better functional and motor performance [33]. However, due to hormones, there is an increase in the amount of body fat by the end of adolescence [33]. Such changes in body composition may have negatively influenced performance in the muscular and cardiorespiratory fitness tests [34] in the group of older girls, exposing them to low physical fitness. In addition, girls around 14 years of age tend to feature unchanging or even reduced levels in motor skill performance [33]. 
G. Minatto, E.L. Petroski, D.A.S. Silva, Health-related physical fitness in adolescents

Girls living in rural areas showed a higher predominance of having low physical fitness levels in two components, whether excess body fat, cardiorespiratory or muscular fitness. In addition, they were more exposed to excess body fat and low muscular fitness or the combination of low muscular and cardiorespiratory fitness levels. These data are not in agreement with the findings of other studies [7, 12], which indicate that girls living in urban areas have a greater likelihood of presenting low physical fitness. It is speculated that the manual labor performed by adolescents living in rural areas contributes to maintaining desirable health-related physical fitness levels. In this study, the fact that girls living in rural areas are more exposed to low physical fitness levels can be explained by the lifestyle adopted by Brazilian girls of German descent. Moreover, the predominance of mechanization has also reduced manual labor, which could contribute to the low physical fitness levels observed in this study.

Boys aged 10-12 years were less exposed low physical fitness levels in the three components compared to those with satisfactory levels. Unlike the results found in this study, other studies separately examining physical fitness components $[9,12]$ found higher chances presenting low physical fitness in young adolescents. According to Petroski et al. [35], approximately one in every four children showed unhealthy body composition, and two in every three showed low levels of aerobic and musculoskeletal fitness. The authors also observed that the prevalence of cardiorespiratory unfitness is greater among older male adolescents (aged 17 to 19 years) than younger male adolescents (aged 15 to 16 years).

During puberty, the increased secretion of androgens in males provides gains in muscle mass; however, there is also an increase in body fat [33], which may have contributed to the lower levels of muscular fitness and greater amount of body fat observed in older boys. Changes in body structures also change flexibility levels. During the growth spurt, there is rapid growth in the anatomical structures of adolescents' bodies, in which bones, muscles and tendons grow at different rates and can result in a temporary reduction in flexibility [33]. In cardiorespiratory fitness, the lower amount of body fat present in early adolescence [33] may have favored younger boys being less exposed to low levels of this component.

No association was found between the cumulative presence of low health-related physical fitness levels and socioeconomic status in this group of Brazilian adolescents with German ancestry. However, different results were found in studies separately analyzing the physical fitness components $[9,36]$. In a state capital in the south of Brazil, adolescents (10-15 years of age) with higher socioeconomic status had better cardiorespiratory fitness levels compared to those belonging in lower socioeconomic groups [9]. European adolescents (12.5 to 17.5 years of age) showed strong and positive correlations between socioeconomic status and physical fitness levels (agility, hand grip strength, lower limb strength and cardiorespiratory fitness), regardless of total body fat and total physical activity [8]. In a study on boys (10-15 years of age) from Poland [37], the physical fitness components differed according to the number of siblings. The results of an endurance shuttle run and bent arm hang test were found to most strongly correlate with the number of siblings, i.e., the more siblings one had, the better their results [37]. Other researchers [38] observed that environmental and sociodemographic conditions are related to adolescents' fitness level. Further research should analyze the health-related physical fitness components in adolescents with homogeneous socio-cultural characteristics and clarify the association between physical fitness and socioeconomic status.

It was observed that the prevalence of presenting low physical fitness levels among the group of Brazilian adolescents with German ancestry is similar to that observed for adolescents from other regions in Brazil, but lower than that observed in European adolescents, in terms of the cardiorespiratory fitness component, assessed by the cutoff points for body fat percentage and cardiorespiratory fitness. The associated factors in this study were similar to those observed in other Brazilian studies, except for area of residence, in which girls living in rural areas were more exposed to concomitant low physical fitness components. Compared to European adolescents, a positive association between physical fitness and socioeconomic level was found. These results may be a consequence of changes in the physical activity patterns performed by adolescents living in rural areas and/or the socio-cultural characteristics of this population, since the physical fitness components differ between different ethnicities [11, 39].

One limitation of this study was its design. Although it is the most suitable for cross-sectional studies, it does not establish causal relationships between physical fitness components and demographic indicators. Moreover, the motivation to carry out physical tests, which was an uncontrollable variable here, could have influenced the results. The tests used to estimate muscular fitness were found to have poor validity [40]; however, they were used in order to be comparable to other studies. Since average physical activity level, aspects of regionalism and ethnicity were not investigated in this study, other associations and inferences could have affected the results.

Among the strengths of this study was that the analyzed adolescent sample is a good representative sample of the population in São Bonifácio since, according to the information from the school office, the dropout rate is $0 \%$. Furthermore, this study was the first to perform analysis of the concomitant presence of low physical fitness components and its associated factors in Brazilian adolescents. This study also featured using the new cutoff points proposed by the FITNESSGRAM for body composition and cardiorespiratory fitness nationwide. 
These results are also useful for developing improved public policies, given that some non-communicable chronic diseases result from the concomitant presence of low physical fitness components. In addition, the results of this study can aid the design of future studies that take into account the sociodemographic characteristics and the stage of sexual maturation of adolescent students.

\section{Conclusions}

The results revealed a high prevalence of the concomitant presence of low physical fitness components, with girls featuring a higher proportion than boys. In the prevalence of the components alone, only low muscular fitness differed between sexes, with girls more exposed to lower levels of this component. Younger girls were less exposed to the combination of featuring excess body fat with low cardiorespiratory fitness. The chances of having excess body fat combined with low muscular fitness, low muscular fitness with low cardiorespiratory fitness, and low physical fitness levels in two of the components regardless of the combination, were higher for adolescents living in rural areas. Boys aged 10-12 years were less exposed to low physical fitness levels in the three studied components when compared to those with satisfactory levels.

\section{Acknowledgements}

We would like to thank the team at the Center for Research in Kinanthropometry and Human Performance and the Coordination of Improvement of Higher Education Personnel (CAPES) for funding this project under grant AUXPEPROCAD/NF110/2010 and for the awarded scholarships.

\section{References}

1. Moreira C., Santos R., Farias Jr J.C., Vale S., Santos P.C., Soares-Miranda L. et al., Metabolic risk factors, physical activity and physical fitness in Azorean adolescents: a cross-sectional study. BMC Public Health, 2011, 11, 214-220, doi: 10.1186/1471-2458-11-214.

2. World Health Organization (WHO). The challenge of obesity in the WHO European Region and the strategies for response: summary. Dinamarca, 2007.

3. Ruiz J.R., Sui X., Lobelo F., Lee D.C., Morrow Jr J.R., Jackson A.W. et al., Muscular strength and adiposity as predictors of adulthood cancer mortality in men. Cancer Epidemiol Biomarkers Prev, 2009, 18 (5), 1468-1476, doi: 10.1158/1055-9965.epi-08-1075.

4. Martins C.L., Silva F., Gaya A.R., Aires L., Ribeiro J.C., Mota J., Cardiorespiratory fitness, fatness, and cardiovascular disease risk factors in children and adolescents from Porto. Eur J Sport Sci, 2010, 10 (2), 121-127, doi: 10.1080/17461390903307842.

5. Kwon S., Burns T.L., Janz K., Associations of cardiorespiratory fitness and fatness with cardiovascular risk factors among adolescents: the NHANES 1999-2002. J Phys Act Health, 2010, 7 (6), 746-753.

6. Shomaker L.B., Tanofsky-Kraff M., Zocca J.M., Field S.E., Drinkard B., Yanovski J.A., Depressive Symptoms and
Cardiorespiratory Fitness in Obese Adolescents. J Adolesc Health, 2012, 50 (1), 87-92, doi: 10.1016/j.jadohealth.2011. 05.015 .

7. Machado-Rodrigues A.M., Coelho-e-Silva M.J., Mota J., Cumming S.P., Riddoch C., Malina R.M., Correlates of aerobic fitness in urban and rural Portuguese adolescents. Ann HumBiol,2011, 38 (4), 479-484, doi:10.3109/03014460. 2011.554865.

8. Jimenez-Pavon D., Ortega F.P., Ruiz J.R., Espana-Romero V., Garcia-Artero E., Moliner-Urdiales D. et al., Socioeconomic status influences physical fitness in European adolescents independently of body fat and physical activity: the HELENA study. Nutr Hosp, 2010, 25 (2), 311-316, doi: $10.3305 / \mathrm{nh} .2010 .25 .2 .4596$.

9. Vasques D.G., Silva K.S., Lopes A.S., Cardiorespiratory fitness of adolescents from Florianópolis, SC [in Portuguese]. Rev Bras Med Esporte, 2007, 13 (6), 376-380, doi: 10.1590/S1517-86922007000600004.

10. Dumith S.C., Azevedo Júnior M.R., Rombaldi A.J., Health-related physical fitness in students from elementary schools of Rio Grande do Sul, Brazil [in Portuguese]. Rev Bras Med Esporte, 2008, 14 (5), 454-459, doi: 10.1590/ S1517-86922008000500011.

11. Santos D.A., Silva A.M., Santa-Clara H., Matias C.N., Fields D.A., Sardinha L.B., Determinant factors of cardiorespiratory fitness in Portuguese adolescents of different ethnicities. Rev Bras Cineantropom Desempenho Hum, 2011, 13 (4), 243-249, doi: 10.5007/1980-0037.2011v1 $3 n 4 \mathrm{p} 243$.

12. Petroski E.L., Silva A.F., Rodrigues A.B., Pelegrini A., Association between low levels of physical fitness and sociodemographic factors in adolescents from rural and urban areas [in Portuguese]. Motricidade, 2012, 8 (1), 5-13, doi: 10.6063/motricidade.8(1).227.

13. Pelegrini A., Silva D.A.S., Petroski E.L., Glaner M.F., Nutritional status and associated factors in schoolchildren living in rural and urban areas [in Portuguese]. Rev Nutr, 2010, 23 (5), 839-846, doi: 10.1590/S1415-527 32010000500014.

14. Pozzobon M.E., Glaner M.F., Carlet R., Physical growth and body fat in boys with different socioeconomic levels [in Portuguese]. Pensar a Prática, 2010, 13 (2), 1-14, doi: 10.5216/rpp.v13i2.8050.

15. Minatto G., Pelegrini A., Silva D.A.S., Silva A.F., Petroski E.L., Association between inadequate body composition and sociodemographic factors in adolescents. Rev Paul Pediatr, 2011, 29 (4), 553-559, doi 10.1590/S010305822011000400013.

16. Andreasi V., Michelin E., Rinaldi A.E.M., Burini R.C., Physical fitness and associations with anthropometric measurements in 7 to 15 -year-old school children [in Portuguese]. J Pediatr, 2010, 86 (6), 497-502, doi: 10.2223/ JPED.2041.

17. Ronque E.R.V., Cyrino E.S., Mortatti A.L., Moreira A., Avelar A., Carvalho F.O. et al., Relationship between cardiorespiratory fitness and indicators of body adiposity in adolescents [in Portuguese]. Rev Paul Pediatr, 2010, 28 (3), 296-302, doi: 10.1590/S0103-05822010000300007.

18. The N.S., Suchindran C., North K.E., Popkin B.M., Gordon-Larsen P., Association of adolescent obesity with risk of severe obesity in adulthood. JAMA, 2010, 304 (18), 2042-2047, doi: 10.1001/jama.2010.1635. 
G. Minatto, E.L. Petroski, D.A.S. Silva, Health-related physical fitness in adolescents

19. Brazil. Government of Santa Catarina, 2002 [in Portuguese]. Available from: http://www.sc.gov.br/conteudo/ santacatarina/historia/paginas/08imigrantes.html [Accessed: $2011 \mathrm{dec}$ 02].

20. Brazilian Institute of Geography ands Statistics (IBGE). Population Sensus, 2010 [in Portuguese]. Available from: http://www.ibge.gov.br/home/estatistica/populacao/ censo2010/populacao_por_municipio.shtm [Accessed: 2010 dec 11].

21. United Nations Program for Development (PNUD). Ranking of the Municipal Development Index of the municipalities of Brazil [in Portuguese]. Available from: http://www.pnud.org.br/atlas/tabelas/index.php [Accessed: 2009 set 12 ].

22. Gore C., Norton K., Olds T., Whittingham N., Birchall K., Clough M. et al., Certification in anthropometry: an Australian Model. In: Norton K., Olds T. (eds.), Anthropometrics [in Portuguese]. Artmed, Porto Alegre 2005, 375-388.

23. Slaughter M.H., Lohman T.G., Boileau R.A., Horswill C.A., Stillman R.J., Van Loan M.D. et al., Skinfold equations for estimation of body fatness in children and youth. Hum Biol, 1988, 60, 709-723.

24. Léger L.A., Mercier D., Gadoury C., Lambert J., The multistage 20 metre shuttle run test for aerobic fitness. J Sports Sci, 1988, 6 (2), 93-101, doi: 10.1080/02640418808729800.

25. Welk G., Meredith M., FITNESSGRAM ${ }^{\circledR} /$ ACTIVITYGRAM: reference guide. $3^{\text {th }}$ ed. The Cooper Institute, Dallas 2008.

26. Standards for Healthy Fitness Zone Revision 8.6 and 9.x. The Cooper Institute, Dallas 2010. Available from: http:// staffweb.esc12.net/ mbooth/resources_general/Coordinated_Fitness\%20Gram/NewStandards_11/Updates_FitnessGram.pdf [Accessed: 2011 nov 20].

27. Brazilian Association of Research Companies (ABEP). Criteria for Economic Ranking in Brazil [in Portuguese], 2010. Available from: http://iestrategy.com/main/wp-content/ uploads/2010/02/CCEB.pdf [Accessed: 2011 jul 17].

28. Tanner J.M., Growth at adolescence: With a general consideration of the effects of hereditary and environmental factors upon growth and maturations from birth to maturity. $2^{\text {nd }}$ ed. Blackwell Scientific Publications, Oxford 1962 .

29. Adami F., Vasconcelos F.A.G., Obesity and early sexual maturation among students from Florianopolis, SC [in Portuguese]. Rev Bras Epidemiol, 2008, 11 (4), 549-560, doi: 10.1590/S1415-790X2008000400004.

30. Dórea V., Ronque E.R.V., Cyrino E.S., Serassuelo Jr H., Gobbo L.A., Carvalho F.O. et al., Health-related physical fitness in students from Jequié, BA, Brazil [in Portuguese]. Rev Bras Med Esporte, 2008, 14 (6), 494-499, doi: 10.1590/ S1517-86922008000600004.

31. Petroski E.L., Silva A.F., Rodrigues A.B., Pelegrini A., Health-related physical fitness in Brazilian adolescents from areas having a medium/low Human Development Index [in Portuguese]. Rev Salud Publica, 2011, 13 (2), 219-228, doi: 10.1590/S0124-00642011000200004.
32. Ortega F.B., Artero E.G., Ruiz J.R., Espana-Romero V., Jimenez-Pavon D., Vicente-Rodriguez G. et al., Physical fitness levels among European adolescents: the HELENA study. Br J Sports Med, 2011, 45 (1), 20-29, doi: 10.1136/ bjsm.2009.062679.

33. Guedes D.P., Jaime Tolentino M.N., Silva A.J.R.M., Motor performance in a sample of Brazilian schoolchildren [in Portuguese]. Motricidade, 2011, 7 (2), 25-38.

34. Moliner-Urdiales D., Ruiz J.R., Vicente-Rodriguez G., Ortega F.B., Rey-Lopez J.P., España-Romero V. et al., Associations of muscular and cardiorespiratory fitness with total and central body fat in adolescents: The HELENA Study. BrJ Sports Med, 2011, 45 (2), 101-108, doi: 10.1136/ bjsm.2009.062430.

35. Petroski E., Silva D., Lima e Silva J., Pelegrini A., Healthrelated physical fitness and associated sociodemographic factors in adolescents from a Brazilian state capital. Hum Mov, 2012, 13 (2), 139-146, doi: 10.2478/v10038-0120015-4.

36. Jiménez-Pavón D., Ortega F.B., Ruiz J.R., Chillón P., Castillo R., Artero E.G. et al., Influence of socioeconomic factors on fitness and fatness in Spanish adolescents: the AVENA study. Int J Pediatr Obes, 2010, 5 (6), 467-473, doi: 10.3109/17477160903576093.

37. Kusy K., Social position and health-related fitness: a crosssectional study of urban boys aged 10-15 years. Hum Mov, 2009, 10 (1), 53-63, doi: 10.2478/v10038-008-0021-8.

38. Półtorak W., The significance of environmental factors for physical development of adolescents. Hum Mov, 2009, 10 (1), 35-45, doi: 10.2478/v10038-008-0023-6.

39. Diniz I.M.S., Lopes A.S., Borgatto A.F., Physical growth and body composition of students from distinct ethnic background of Rio Grande do Sul state, Brazil [in Portuguese]. Rev Bras Cineantropom Desempenho Hum, 2008, 10 (1), 12-18.

40. Ruiz J.R., Castro-Pinero J., Espana-Romero V., Artero E.G., Ortega F.B., Cuenca M.M. et al., Field-based fitness assessment in young people: the ALPHA health-related fitness test battery for children and adolescents. Br J Sports Med, 2011, 45 (6), 518-524, doi: 10.1136/bjsm.2010.075341.

Paper received by the Editors: May 3, 2012

Paper accepted for publication: September 4, 2012

\section{Correspondence address}

\section{Giseli Minatto}

Universidade Federal de Santa Catarina (UFSC)

Centros de Desportos (CDS)

Núcleo de Cineantropometria e Desempeno

Humano (NuCiDH)

Campus Universitário, Trindade, Caixa Postal 476

CEP 88040-900, Florianópolis, SC, Brasil

e-mail: gminatto@gmail.com 